\title{
Natural and Synthetic Polymers Assisted Development of Lurasidone Hydrochloride Intranasal Mucoadhesive Microspheres
}

\author{
Shoaib Khan, Purushottam Shridhar Gangane*, Debarshi Kar Mahapatra, Nilesh Manoharrao Mahajan
}

Department of Pharmaceutics, Dadasaheb Balpande College of Pharmacy, Nagpur, Maharashtra, INDIA.

\begin{abstract}
Objectives: To avoid the first-pass metabolism of the drug (lurasidone $\mathrm{HCl}$ ) and further improving its contact time with the nasal mucosa, intranasal mucoadhesive microspheres were developed by using natural (chitosan) and synthetic (Eudragit L 100) polymers by spray-drying method. The study aims to enhance the systemic drug absorption via the nasal membrane and to further evaluate the effect of polymers on the drug release profile. Methodology: The microspheres of each polymer were prepared in three different ratios with one blank batch, where the effect of concentration of polymer was assessed with all six formulations with respect to change in particle size and entrapment efficiency. The prepared microspheres were assessed for the essential parameters such as particle size, production yield, entrapment efficiency and histopathological study. The excipients-drug substance compatibility was assessed and their associative behavior was comprehensively studied by Differential Scanning Calorimetry (DSC), X-ray Diffraction (XRD) and Scanning Electron Microscopy (SEM). Results: The particle size analysis also revealed that all the formulations had particle size in the range of $10-15 \mu \mathrm{m}$ which is suitable for intranasal administration. The optimized batch of chitosan microspheres $(\mathrm{CH}-2)$ and optimized batch of Eudragit L 100 microspheres (EU-1) formulations showed maximum drug loading of $68.3 \%$ and $74.9 \%$ whereas the cumulative drug release was found to be $76.36 \%$ and $80.18 \%$, respectively. Conclusion: From the obtained results, it was concluded that the study showed a satisfactory attempt to formulate mucoadhesive microspheres with improved absorption rate and contact time of drug with nasal mucosa. Key words: Lurasidone, Intranasal, Mucoadhesive, Microsphere, Drug absorption.
\end{abstract}

\section{INTRODUCTION}

Lurasidone hydrochloride is a thiazole azapiron derivative that acts on $\mathrm{D}_{2}$ and serotonin $5 \mathrm{HT}_{2 \mathrm{~A}}$ receptor as a complete antagonist and is used in the management of psychiatric conditions. ${ }^{1}$ It is having a poor oral bioavailability about $19 \%$ due to first-pass metabolism and its plasma half-life is about $18-40 \mathrm{hr}^{2}$ The nasal cavity offers an attractive alternative route to parenteral administration and has attracted wide attention as a reliable, safe, non-invasive and convenient route to accomplish faster and higher levels of drug absorption. ${ }^{3}$

Intranasal therapy has been an accepted form of treatment in the Ayurvedic system of Indian medicine. ${ }^{4}$ The nasal mucosa exhibits greater permeability than other mucosal surfaces including the various regions of the gastrointestinal tract, buccal and vaginal cavities, which provides rapid systemic drug absorption and quick onset of action. ${ }^{5}$ The nasal mucosa is well supplied with a rich vasculature which directly flows into the systemic circulation thus avoiding hepatic metabolism. ${ }^{6}$ Recently, it has been shown that many drugs have better bioavailability by nasal route than oral route. ${ }^{7}$

Microsphere technology is one of the specialized systems becoming popular for designing nasal products. ${ }^{8}$ The microspheres swell in contact with nasal mucosa and form a gel which controls the rate
Submission Date: 10-07-2019; Revision Date: 30-10-2019; Accepted Date: 26-11-2019

DOI: 10.5530/ijper.54.1.25 Correspondence: Dr. Purushottam S Gangane, Associate Professor, Department of Pharmaceutics, Dadasaheb Balpande College of Pharmacy, Nagpur-440037,

Maharashtra, INDIA

Phone: +91-9420338543

E-mail: p.gangane@gmail.com

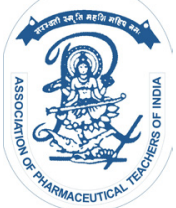

www.ijper.org 
of clearance from the nasal cavity as it may provide prolonged contact with the nasal mucosa and thus enhances absorption and bioavailability, where the nasal mucosa is dehydrated due to moisture uptake by the microspheres. ${ }^{9}$ The result in reversible shrinkage of the cells, providing a temporary opening of tight junctions that increases the absorption of drugs. ${ }^{10}$

Intranasal mucoadhesive microspheres have emerged as alternative dosage forms for the psychotic patients who experience difficulties in administration of medicine by swallowing oral solid dosage forms such as tablets, capsules and syrups as compared to nasal administration of very fine powdered microspheres. ${ }^{11}$ These microspheres retained for prolong period of time and directly delivers the drug at brain via nose to brain pathways. ${ }^{12}$ As far as the nasal microspheres are concerned, spray drying is an important method for its preparation. It is more advantageous because it is a one-step process having high drug loading capacity and reproducibility. ${ }^{13}$ Moreover, the process is more feasible for scaling up compared to other microsphere fabrication methods.

The aim of this work was to develop natural (i.e. chitosan) and synthetic (i.e. Eudragit L 100) polymer-based mucoadhesive microspheres of lurasidone hydrochloride in different drug-to-polymer ratios (1:2 to 1:4) with one blank batch of both polymers were prepared by spraydrying technique for the nasal administration. The prepared mucoadhesive microspheres were evaluated in terms of morphology, production yield, particle size, drug loading, entrapment efficiency, swelling property, in vitro mucoadhesion, in vitro drug release, ex vivo drug permeation and histopathological studies. The prepared microspheres were characterized by differential scanning calorimetry, scanning electron microscopy and X-ray diffraction study.

\section{MATERIALS AND METHODS}

\section{Materials}

Lurasidone $\mathrm{HCl}$ was received as a kind gift from Emcure Ltd., Pune, India. Chitosan (degree of deacetylation $>75 \%$ ), Eudragit L 100, methanol and dichloromethane were purchased from Loba Chemie, Mumbai, India. All other chemicals, solvents and reagents used in the study were of analytical grade. Double distilled water (Borosil, India) was employed for the experiment.

\section{Instruments}

Spray dryer (Lu-222 Advanced, Labultima, Mumbai, India), Mechanical stirrer (Remi Laboratory Ltd., Mumbai, India) UV/Vis spectrophotometer (Shimadzu UV-1800, Japan), pH meter (Labtronics LT-10, New Delhi,
India), Digital Motic microscope (DMW2-223, Motic Instruments Inc., Canada) and Franz Diffusion Cell (Orchid Scientific, Nashik, India) were used for the formulation and characterization purpose.

\section{Preparation of mucoadhesive microspheres}

Chitosan (CH) microspheres and Eudragit L 100 (EU) microspheres were prepared by spray-drying technique (Table 1). The chitosan solution $(1 \% \mathrm{w} / \mathrm{v})$ was prepared in aqueous glacial acetic acid by continuous stirring using a sharp blade mechanical stirrer, this solution was filtered through $0.45 \mu \mathrm{m}$ Millipore filter paper then the drug was dispersed in the polymeric solution and stirred. A sufficient amount of 25\% (v/v) aqueous glutaraldehyde (cross-linking agent) was added slowly with continuous stirring. In the case of Eudragit L 100 microspheres required quantity of Eudragit L 100 was dissolve in methanol by continuous stirring with the help of sharp blade mechanical stirrer then the drug was added to the polymeric solution and stirred continuously. The drug-loaded microspheres were obtained by spraying the feed solution with a spray dryer using a standard $0.7 \mathrm{~mm}$ nozzle. The solution was fed to the nozzle with a peristaltic pump, atomized by the force of compressed air and blown together with heated air to the chamber where the solvent in the droplets was evaporated. The dried microparticles were harvested from the apparatus collector and kept in a desiccator. The process parameters of the spray-drying technique includes inlet temperature of $80-85^{\circ} \mathrm{C}$, outlet temperature $60-65^{\circ} \mathrm{C}$, aspirator speed $40-50 \%$ and feed pump speed 8-10 $\mathrm{ml} \mathrm{min}^{-1} .{ }^{14}$ The formulation batches of chitosan microspheres and Eudragit L 100 microspheres of lurasidone $\mathrm{HCl}$ shown in Table 1, where CH-B and EU-B are blank microspheres of both formulations, respectively.

\begin{tabular}{|c|c|c|c|c|}
\hline $\begin{array}{l}\text { Types of } \\
\text { polymer }\end{array}$ & $\begin{array}{c}\text { Formulation } \\
\text { Batch }\end{array}$ & $\begin{array}{l}\text { Drug : } \\
\text { Polymer } \\
\text { ratio }\end{array}$ & $\begin{array}{l}\text { Drug } \\
\text { (mg) }\end{array}$ & $\begin{array}{c}\text { Polymer } \\
\text { (mg) }\end{array}$ \\
\hline \multirow{4}{*}{ Chitosan } & $\mathrm{CH}-\mathrm{B}$ & - & - & 2000 \\
\hline & $\mathrm{CH}-1$ & $1: 2$ & 1000 & 2000 \\
\hline & $\mathrm{CH}-2$ & $1: 3$ & 1000 & 3000 \\
\hline & $\mathrm{CH}-3$ & 1: 4 & 1000 & 4000 \\
\hline \multirow{4}{*}{$\begin{array}{l}\text { Eudragit L } \\
100\end{array}$} & EU-B & - & - & 2000 \\
\hline & EU-1 & $1: 2$ & 1000 & 2000 \\
\hline & EU-2 & 1: 3 & 1000 & 3000 \\
\hline & EU-3 & $1: 4$ & 1000 & 4000 \\
\hline
\end{tabular}




\section{Characterization of microspheres Production yield}

The production yields of microspheres of various formulation batches were calculated using the weight of the final product after drying with respect to the initial total weight of the drug and polymer used for the preparation of microspheres. ${ }^{15}$

$$
\% \text { Production yield }=\frac{\begin{array}{c}
\text { Practical mass } \\
(\text { final product })
\end{array}}{\begin{array}{l}
\text { Theoretical mass } \\
(\text { polymer }+ \text { drug })
\end{array}} \times 100
$$

\section{Particle size analysis}

A microscopic image analysis technique for the determination of particle size was applied. The particle size was determined by a Motic digital microscope set with a $1 / 3$ " CCD camera imaging accessory as well as computer-controlled image analysis software (Motic images plus 2000, 1.3 version). The microspheres were dispersed on a microscope slide and the microscopic field was scanned by a video camera. By using the software, the images of the scanned field are analyzed. ${ }^{16}$

\section{Drug loading and entrapment efficiency}

The weighed amount of microspheres of each formulation batch was dissolved in methanol and kept overnight to extract lurasidone $\mathrm{HCl}$ and the solution was filtered through the Whatman filter paper. $1 \mathrm{~mL}$ of this solution was withdrawn and diluted to $10 \mathrm{~mL}$ with methanol. This solution was assayed for drug loading by UV spectrophotometer at $229 \mathrm{~nm}$ methanol as a blank and percent drug loading and entrapment efficiency were calculated using the below formula:

$$
\% \text { Drug loading }=\frac{\begin{array}{l}
\text { Actual amount of drug } \\
\text { loaded in microspheres }
\end{array}}{\begin{array}{l}
\text { Weighed quantity } \\
\text { of microspheres }
\end{array}} \times 100
$$$$
\% \text { Entrapment efficiency }=\frac{M_{\text {actual }}}{M_{\text {theoretical }}} \times 100
$$

Where $\mathrm{M}_{\text {actual }}$ is the actual drug content in a weighed quantity of powder of microspheres and theoretical amount of drug in microspheres calculated from the quantity added in the fabrication process is $\mathrm{M}_{\text {therotical }}{ }^{17}$

\section{Swelling property}

The swelling property of microspheres in physiological media (simulated nasal fluid) was determined by allowing them to swell to their equilibrium, calculated by using the formula: ${ }^{18}$

$$
\begin{gathered}
\alpha=(\text { Ws-Wo }) / \text { Ws } \\
I=\alpha \times 100
\end{gathered}
$$

Where, $\alpha=$ degree of swelling; Ws $=$ weight of microspheres after swelling; Wo = initial weight of microspheres; and I $=\%$ swelling index.

\section{In vitro mucoadhesion study}

Falling liquid film technique was used to determine the mucoadhesive property of prepared microspheres. A freshly cut piece $2 \mathrm{~cm}^{2}$ of goat nasal mucosa within $1 \mathrm{hr}$ of sacrificing the animal was cleaned by washing with isotonic saline solution. An accurately weighed quantity of microspheres $(100 \mathrm{mg})$ was placed on the mucosal surface, which was attached over a polyethylene plate. About $100 \mu \mathrm{L}$ of the simulated nasal electrolyte solution was put on microspheres and this plate was incubated for $15 \mathrm{~min}$ in desiccators at $90 \%$ relative humidity to allow the polymer to interact with the membrane and finally fixed at an angle of $45^{\circ} \mathrm{C}$ relative to the horizontal plane. Phosphate buffer $(\mathrm{pH}$ 6.6) previously warmed to $37 \pm 5^{\circ} \mathrm{C}$ was circulated all over the microspheres and membrane at the rate of $1 \mathrm{ml} / \mathrm{min}$. After $1 \mathrm{hr}$, the amount of drug in the collected perfusate was spectrophotometrically determined. The weight of washed-out microspheres was determined and percent mucoadhesion was calculated by the following formula: ${ }^{19}$

$$
\begin{aligned}
& \text { Amount of washout } \\
& \% \text { in vitro mucoadhesion }=\frac{\text { drug in perfusate }}{\text { Amount of applied }} \times 100 \\
& \text { drug in microspheres }
\end{aligned}
$$

\section{X-Ray Diffraction}

X-ray diffraction patterns of the plain drug, blank microsphere and drug-loaded microspheres were recorded on an X-ray diffractometer. The samples were irradiated with monochromatized $\mathrm{Cu}-\mathrm{K} \alpha$ radiation and analyzed between $3-60^{\circ} \mathrm{C}(2 \theta)$. The voltage and current used were $40 \mathrm{kV}$ and $35 \mathrm{~mA}$, respectively. ${ }^{20}$

\section{Differential Scanning Calorimetry}

The thermal behaviors of pure drug, blank microspheres and drug-loaded microspheres were studied using a differential scanning calorimeter. The thermograms were obtained at a heating rate of $10^{\circ} \mathrm{C} / \mathrm{min}$ over a temperature range $30-300^{\circ} \mathrm{C}$ under an inert atmosphere flushed with nitrogen at a rate of $20 \mathrm{ml} / \mathrm{min}^{21}$ 


\section{Scanning Electron Microscopy}

The surface morphology of microspheres was studied using a scanning electron microscopy. The powder of microspheres was dusted onto double-sided tape on an aluminum stub and coated with gold using a cold sputter coater in SEM chamber to a thickness of $4 \mathrm{~A}^{\circ}$ and photomicrographs are captured by operating at an accelerating voltage of $20 \mathrm{kV}$ electron beam. The obtained photomicrographs were examined at 500x and 7000x magnifications. ${ }^{22}$

\section{In vitro drug release study}

The in vitro drug release study of microspheres was performed using a glass-fabricated Franz diffusion cell across the dialysis membrane (Mw cut-off 12,000 $14,000)$ as a diffusion barrier. The membrane was equilibrated before carefully dispersing the microspheres into the donor compartment. The receptor compartment was filled with Phosphate Buffer Solution (PBS) (pH 6.6) that was within the $\mathrm{pH}$ range in the nasal cavity. The donor compartment was placed in such a way that it just touched the diffusion medium in the receptor compartment. The temperature was maintained at $37 \pm 1^{\circ} \mathrm{C}$ using a circulating water bath. The samples were periodically withdrawn from the receptor compartment, replaced with the same amount of fresh pre-warmed buffer solution and assayed using UV spectrophotometer at $229 \mathrm{~nm}^{23}$

\section{Model fitting analysis}

To study the release kinetics of optimized batch of chitosan microspheres (CH-2) and Eudragit L 100 microspheres (EU-1), data obtained from in vitro drug release studies were plotted in various kinetic models: zero-order (Equation 1) as cumulative amount of drug released vs time, first-order (Equation 2) as log cumulative percentage of drug remaining vs. time and Higuchi's model (Equation 3) as cumulative percentage of drug released vs square root of time. ${ }^{24}$

\section{Zero-order model}

$$
\mathrm{C}=\mathrm{K}_{0} \mathrm{t}
$$

Where $\mathrm{K}_{0}$ is the zero-order rate constant expressed in units of concentration/ time and $\mathrm{t}$ is the time in minutes. A graph of concentration vs. time would yield a straight line with a slope equal to $\mathrm{K}_{0}$ and intercept the origin of the axes.

\section{First-order model}

$$
\log C=\log _{0}-\mathrm{Kt} / 2.303
$$

Where $\mathrm{C}_{0}$ is the initial concentration of the drug, $\mathrm{K}$ is the first order constant and $t$ is the time.

\section{Higuchi model}

$$
\mathrm{Q}_{\mathrm{t}}=\mathrm{K}_{\mathrm{t}}^{1 / 2}
$$

Where $Q_{t}$ is the amount of drug release in time $t$, $\mathrm{K}$ is the kinetic constant and $\mathrm{t}$ is the time in minutes. A more stringent test was used to distinguish between the mechanisms of drug release. The release data were fitted to the Peppas exponential model as log cumulative percentage of drug released vs log time (Equation 4). The release exponent $\mathrm{n}$ and $\mathrm{K}$ value were calculated through the slope of the straight line. If the exponent $n=0.43$ then the drug release mechanisms Fickian diffusion, if $0.43<n<0.85$ then it is non-Fickian or anomalous diffusion, if $n<0.85$ mechanism is non-Fickian case II diffusion.

$$
\mathrm{Mt}=\mathrm{M} 1 \frac{1 / 4 \mathrm{Kt}^{\mathrm{n}}}{}
$$

\section{Ex vivo permeation study}

The ex vivo drug permeation study of microspheres was performed using a glass-fabricated Franz diffusion cell across goat nasal mucosa as a diffusion barrier. The mucosa was equilibrated before carefully dispersing the weighed quantity of $10 \mathrm{mg}$ microspheres into the donor compartment. The receptor compartment was filled with phosphate buffer solution ( $\mathrm{pH}$ 6.6) that was within the $\mathrm{pH}$ range in the nasal cavity. The donor compartment was placed in such a way that it just touched the diffusion medium in the receptor compartment. The temperature was maintained at $37 \pm 1^{\circ} \mathrm{C}$ using a circulating water bath. The samples were periodically withdrawn from the receptor compartment, replaced with the same amount of fresh pre-warmed buffer solution and assayed using UV spectrophotometer at $229 \mathrm{~nm} .^{25}$

\section{Histopathology Study}

The goat nasal mucosa obtained from the local slaughterhouse within $1 \mathrm{hr}$ of sacrificing the animal was cleaned by washing with isotonic saline solution. After 1 hr of applying the drug-loaded microspheres, the nasal mucosa was fixed in 10\% neutral carbonate buffered formalin solution, routinely processed and embedded in paraffin to assure optimal conditions for the viability of the tissue. Paraffin sections $(7 \mathrm{~mm})$ were cut on glass slides and stained with haematoxylin and eosin. Sections were examined under a light microscope, to detect any damage to the tissue during in vitro permeation study. ${ }^{26}$

\section{Statistical analysis}

One-way Analysis of Variance (ANOVA) with Least Significant Difference (LSD) multiple comparison procedure was applied in this study by using InStat 
GraphPad Prism v8.0 software. The statistical probability $(P)$ value of $<0.05$ was considered as significant difference.

\section{RESULTS AND DISCUSSION}

\section{Formulation}

The spray-drying technique described here appears to be a suitable method for the preparation of chitosan and Eudragit L 100 microspheres loaded with lurasidone $\mathrm{HCl}$. It is the one-step process, easy and rapid also it combines drying of the feed and embedding of the drug into a one-step operation. The spray-dried microspheres of chitosan appeared as a yellowish-brown and off-white powder for Eudragit L 100 microspheres.

\section{Characterization of microspheres Production yield}

The production yield of mucoadhesive microspheres was found to be between $23 \%$ to $30.4 \%$ for chitosan microspheres and $21 \%$ to $33.8 \%$ for Eudragit L 100 microspheres, respectively (Figure 1A). Due to the loss of material in spray drying method maximum production yield for chitosan microspheres was found to be $30.4 \%$ and $33.8 \%$ for Eudragit L 100 microspheres. Increasing the concentration of the polymer leads to a slight increase in the yield. ${ }^{27}$

\section{Particle size}

An average particle size of microspheres ranged from 10 to $15 \mu \mathrm{m}$, such particles are considered to be suitable for nasal administration. The average particle size of microspheres ranged from $9.89 \mu \mathrm{m}$ to $15.3 \mu \mathrm{m}$ (Figure 1B) and microscopic image of microspheres (Figure 2). In spray drying method particle size is mainly depends on the diameter of spraying nozzle; hence the diameter of the nozzle was selected as $0.7 \mathrm{~mm}$, as the diameter of nozzle decreases particle size also gets decreases irrespective of the concentration of mucoadhesive polymer.

\section{Drug Loading}

The drug loading of mucoadhesive microspheres were found in the range of $49.6 \%$ to $68.3 \%$ for chitosan microspheres and $70.88 \%$ to $95.78 \%$ for Eudragit L 100 microspheres, respectively. In the case of chitosan microspheres, the maximum drug loading was found to be $68.3 \%$ with the drug to polymer ratio $1: 3$ of formulation $\mathrm{CH}-2$ and $95.78 \%$ with the drug to polymer ratio 1:2 in formulation EU-1 of Eudragit L 100 microspheres (Figure 1C).

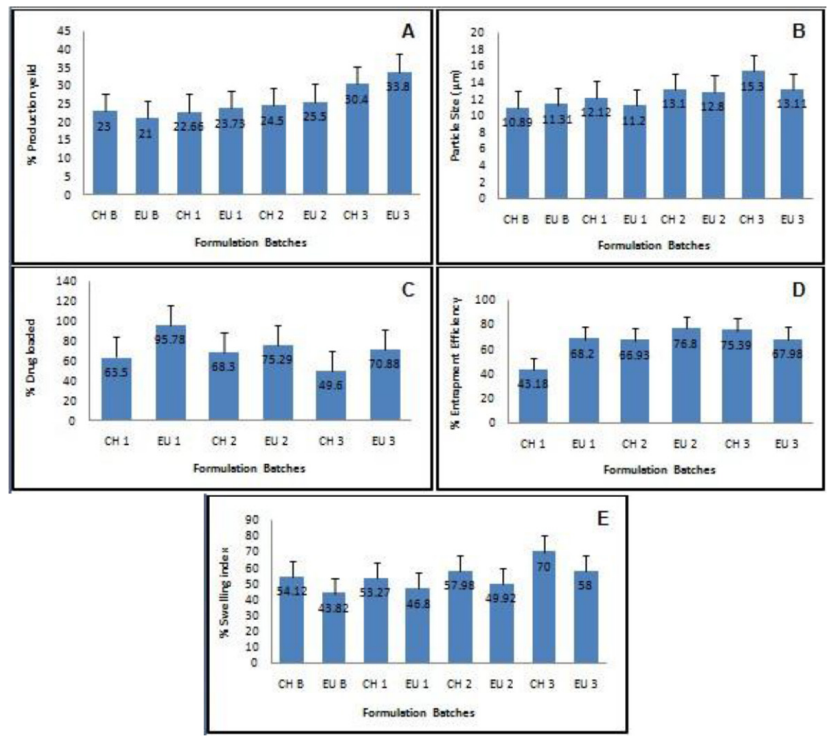

Figure 1: Pharmaceutical characteristics of the prepared intranasal mucoadhesive microspheres: (A) \% production yield; (B) particle size; (C) \% drug loaded; (D) \% entrapment efficiency; and $(E) \%$ swelling index.

\section{Entrapment efficiency}

The entrapment efficiency of mucoadhesive microspheres was found in the range of $43.18 \%$ to $75.39 \%$ for chitosan microspheres and $68.2 \%$ to $76.80 \%$ for Eudragit L 100 microspheres, respectively. In the case of chitosan microspheres, the maximum entrapment efficiency was found to be $75.39 \%$ as a result of higher concentration of drug to polymer ratio 1:4 of batch $\mathrm{CH}-3$ and the maximum entrapment efficiency in Eudragit L 100 microspheres was found to be $76.80 \%$ of batch EU-2 (Figure 1D).

\section{Swelling property}

The swelling property of the mucoadhesive microsphere ranged from $53.27 \%$ to $70 \%$ for chitosan microspheres and $43.82 \%$ to $58 \%$ for Eudragit L 100 microspheres. All obtained microspheres rapidly swelled in Simulated Nasal Fluid (SNF). The swelling capacity of the microspheres was determined by polymer content in the preparation. The amount of polymer affects the swelling of microspheres. It has been observed that as the amount of chitosan and Eudragit L 100 increases, the swelling property also increases (Figure 1E). ${ }^{28}$

\section{In vitro mucoadhesion study}

The mucoadhesion study was carried out to ensure the adhesion of formulation to the nasal mucosa for a prolonged period of time at the site of absorption. The results showed that the mucoadhesive microspheres adequately adhere to the nasal mucosa. The ratio of 


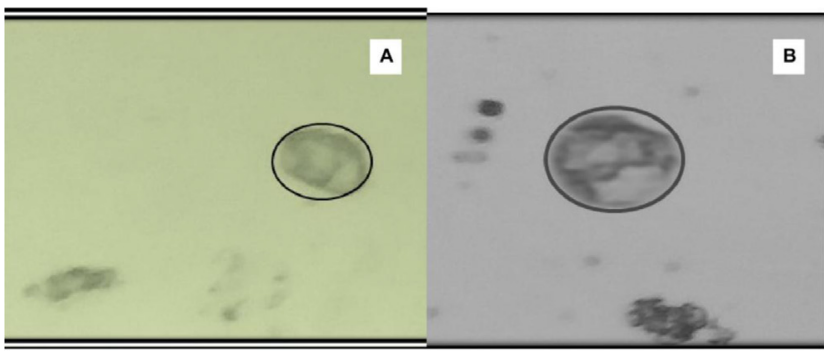

Figure 2: Microscopic image of microspheres: (A) drug-loaded chitosan microsphere (B) drug-loaded Eudragit L 100 microsphere.

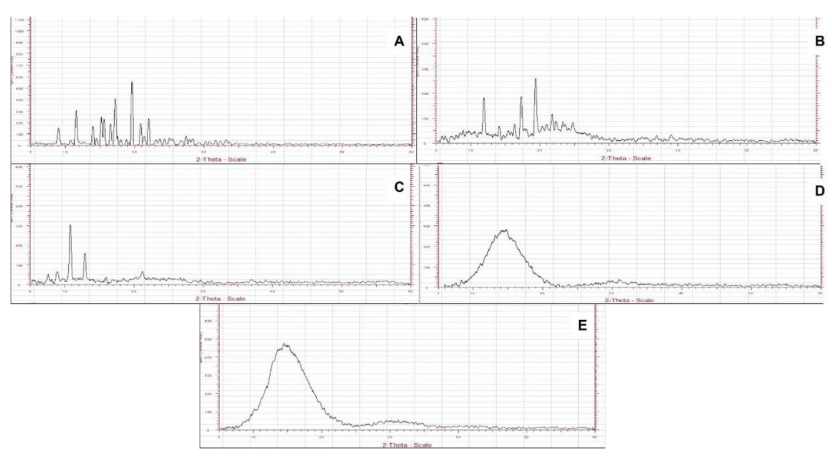

Figure 3: Powder X-ray diffraction spectra of

(A) pure drug lurasidone $\mathrm{HCl}$; (B) blank chitosan microsphere; (C) drug-loaded chitosan microsphere; (D) blank Eudragit L 100 microsphere; and (E) drug-loaded Eudragit L 100 microsphere.

the adhered microspheres was expressed as percent mucoadhesion. From the optimized batch of both polymers, the percentage of the originally applied mass of microspheres attached to the nasal mucosa was found to be about $72 \%$ and $67 \%$ for chitosan microspheres and Eudragit L 100 microspheres, respectively and could adequately adhere on goat nasal mucosa. The increasing polymer ratio, higher mucoadhesion percentages were obtained. This could be attributed to the availability of a higher amount of polymer for interaction with mucus. ${ }^{29}$

\section{XRD Studies}

The X-ray diffraction pattern of pure drug lurasidone $\mathrm{HCl}$, blank microsphere and drug-loaded microspheres of both polymers was recorded on an X-ray diffractometer. The distinctive sharp peaks of the drug were observed at diffraction angles $11.486^{\circ}, 13.914^{\circ}$ and $16.466^{\circ}$ on the $2 \theta$ scale (Figure 3), illustrating the typical crystalline nature of the drug. The sample microspheres showed a broad peak of $19.329^{\circ}$ for indicating the amorphous state of the polymer. The absence of crystalline peaks of lurasidone $\mathrm{HCl}$ in drug-loaded microspheres confirmed that the drug was molecularly

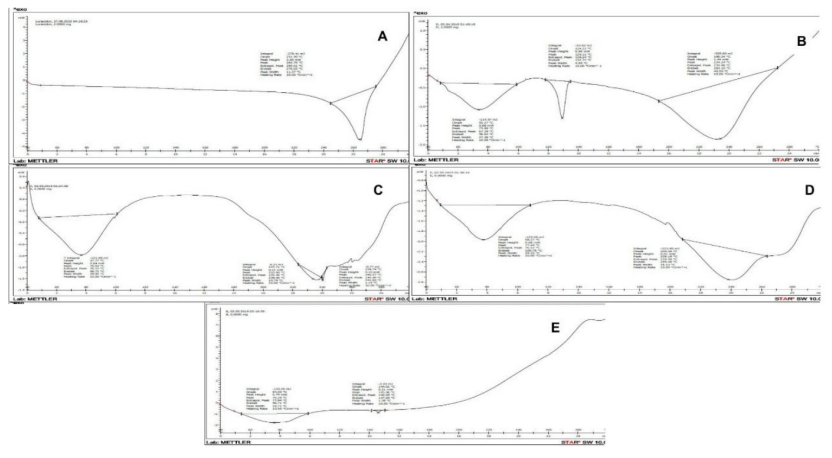

Figure 4: DSC thermogram of (A) pure drug lurasidone $\mathrm{HCl}$; (B) blank chitosan microsphere; (C) drug-loaded chitosan microsphere; (D) blank Eudragit L 100 microsphere; and (E) drug-loaded Eudragit L 100 microsphere.

dispersed in the polymer and conversion of the drug into the amorphous form takes place. ${ }^{30}$

\section{Thermal analysis}

The DSC thermogram of the pure drug, blank microspheres of both polymer and drug-loaded mucoadhesive microspheres of chitosan and Eudragit L 100 are depicted. Lurasidone $\mathrm{HCl}$ showed sharp melting endotherm at $264.75^{\circ} \mathrm{C}$ where thermogram of blank chitosan microspheres shows three endothermic peaks at $73.80^{\circ} \mathrm{C}, 129.12^{\circ} \mathrm{C}$ and $234.24^{\circ} \mathrm{C}$, respectively. The drug-loaded chitosan microspheres showed three sharp melting endotherms at $76.64^{\circ} \mathrm{C}, 233.60^{\circ} \mathrm{C}$ and $240.27^{\circ} \mathrm{C}$ (Figure 4), respectively. The thermo gram presented drug and polymer compatibility with each other. The blank Eudragit L 100 microspheres showed two endothermic peaks at $77.44^{\circ} \mathrm{C}$ and $238.19^{\circ} \mathrm{C}$ and drug-loaded Eudragit L 100 microspheres showed two sharp melting endotherms at $76.28^{\circ} \mathrm{C}$ and $145.96^{\circ} \mathrm{C}$. The thermo gram of drug-loaded microspheres did not appear. DSC studies revealed that the drug was molecularly dispersed inside the microspheres. ${ }^{31}$

\section{Morphological examination}

SEM was done for studying the morphology and surface characteristics of prepared microspheres. Scanning electron microscopy photomicrographs (Figure 5) suggested that these microspheres had no hole or rupture on the surface, such morphology would result in slow clearance and good deposition pattern in the nasal cavity.

\section{In vitro drug release study}

The drug release profile from various formulation batches of chitosan microspheres (Figure 6A) and Eudragit L 100 microspheres (Figure 6B) are described. From the in vitro drug release profile, the formulation $\mathrm{CH}-2$ of chitosan microspheres had the highest 


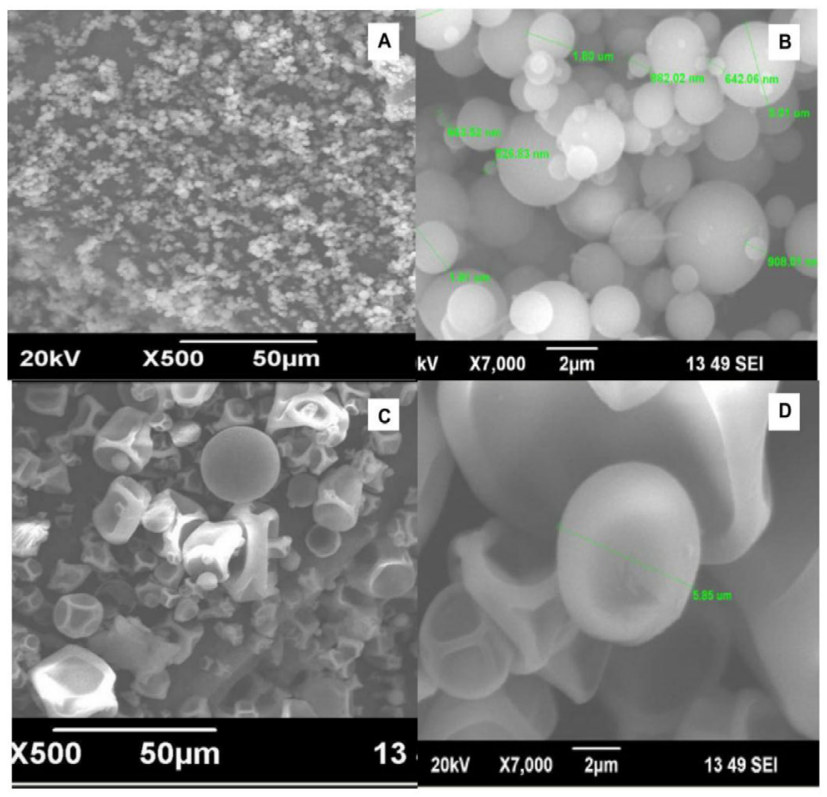

Figure 5: Scanning electron micrograph: (A) drug-loaded chitosan microsphere at 500x resolution; (B) drug-loaded chitosan microsphere at $7000 x$ resolution; (C) drug-loaded Eudragit L 100 microsphere at 500x resolution; and (D) drugloaded Eudragit L 100 microsphere at $7000 x$ resolution.

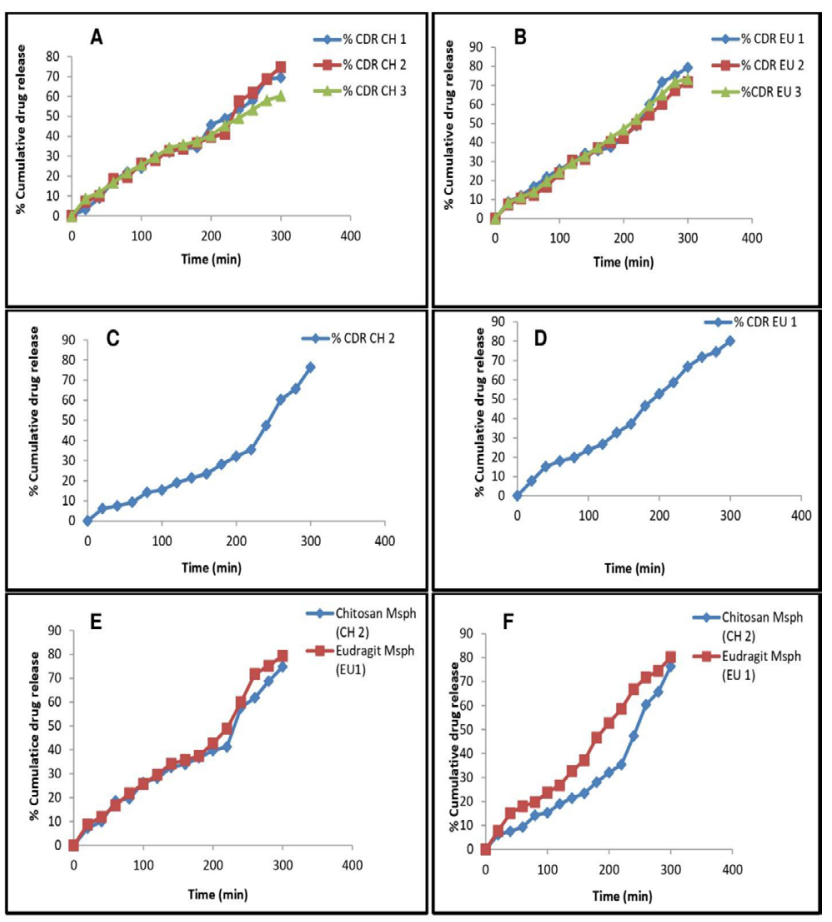

Figure 6: Release attributes (A) drug release profiles of chitosan microsphere batches; (B) drug release profiles of Eudragit L 100 microsphere batches; (C) Ex vivo drug permeation profile of optimized batch $\mathrm{CH}-2$ of chitosan microspheres; (D) Ex vivo drug permeation profile of optimized batch EU-1 of Eudragit L 100 microspheres; (E) In vitro comparative drug release profile of optimized batch of chitosan and Eudragit microspheres; and (F) Ex vivo comparative drug permeation profile of optimized batch of chitosan and Eudragit microspheres. cumulative drug release of $74.836 \%$ and formulation EU-1 of Eudragit L 100 microspheres had 79.481\% cumulative drug release within $5 \mathrm{hr}$ as compared to other formulations, hence these two batches are selected as optimized batches. In order to investigate the drug release mechanism, the release data were fitted to models representation zero-order, first-order and Higuchi square root of time.

\section{Ex vivo drug permeation study}

The ex vivo permeation study of the optimized batch of both polymer-based formulations was carried out by using goat nasal mucosa. The formulation $\mathrm{CH}-2$ of chitosan microspheres had the highest cumulative drug release of $76.364 \%$ (Figure 6C) and formulation EU-1 of Eudragit L 100 microspheres had 80.182\% (Figure 6D) cumulative drug release within $5 \mathrm{hr}$.

\section{Drug release kinetics and drug release mechanism}

The drug release data were fitted to kinetic models in order to investigate the drug release kinetics. It was found that the in vitro drug release of optimized microspheres formulation $\mathrm{CH}-2$ and EU-1 was best fitted to the zero-order kinetic model, it indicates that drug releases at a constant rate and the $n$-value indicates both formulations follows the non-Fickian mechanism of drug release.

\section{In vitro comparative drug release profile of optimized batch of chitosan and Eudragit microspheres}

The in vitro comparative study reveals that the chitosan microsphere batch $\mathrm{CH}-2$ showed $74.83 \%$ and Eudragit L 100 microsphere batch EU-1 showed 79.41\% cumulative drug release within $5 \mathrm{hr}$ and follows zero-order kinetics (Figure 6E).

\section{Ex vivo comparative drug permeation study of optimized batch of chitosan and Eudragit microspheres}

The ex vivo comparative drug permeation study reveals that the chitosan microsphere batch $\mathrm{CH}-2$ showed 76.36\% and Eudragit L 100 microsphere batch EU-1 showed the highest $80.18 \%$ cumulative drug release within $5 \mathrm{hr}$ (Figure 6F).

\section{Histopathology Studies}

Histopathology study showed control mucosa that is untreated nasal mucosa stained with haematoxylin-eosin and the effect of formulation on goat nasal mucosa, after applying the drug-loaded microsphere. The ciliated respiratory epithelium and normal goblet cell were observed this confirms that formulation does not cause 


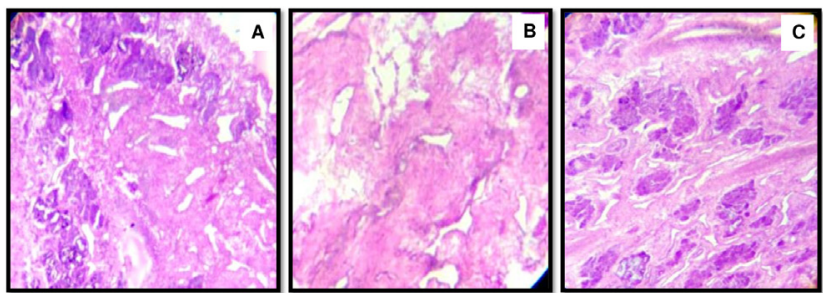

Figure 7: Histological studies: (A) Untreated goat mucosa; (B) chitosan microsphere treated goat mucosa; and (C) Eudragit L 100 microsphere treated goat mucosa.

any deleterious response and adverse effect on nasal mucosa (Figure 7).

\section{CONCLUSION}

The study regarding the effective delivery and possible bioavailability enhancement of lurasidone hydrochloride was taken into account, hypothesized, co-related and developed successively by fabricating microspheres by using a natural polymer (chitosan) as well as a synthetic polymer (Eudragit L 100). Several advantages and disadvantages have been perceived from polymeric usage (natural vs. synthetic) in context to in vitro drug release, mucoadhesive properties and swelling attributes (from optimized formulation). However, no instant opinion can be given as chitosan microspheres had shown better mucoadhesive property as compared to synthetic microspheres; while synthetic microspheres had the highest cumulative drug release due to its high drug loading. The technique of product development through conventional spray drying method have been found to be a promising alternative approach than any other ways in developing this non-conventional dosage form. The explanation for plausible bioavailability and duration of action may be concluded from the fact that after getting contact with the nasal mucosa, microspheres formulations of lurasidone hydrochloride are believed to form a viscous gel by withdrawing water from the nasal mucosa and interaction with cations present in nasal secretions. The resultant gel formation will effectually decrease the biliary clearance rate and as a consequence the residence time of the formulation at the nasal mucosa is prolonged with no deleterious effect or toxic response (as evidenced from histopathological studies). The study will definitely open new avenues and dimensions towards the enhancement of bioavailability, targeting of drugs, extending the drug release and enhancing the half-life of drugs through microsphere formulations.

\section{ACKNOWLEDGEMENT}

The authors would like to acknowledge President, Ambe Durga Educational Society, Nagpur and Principal, Dadasaheb Balpande College of Pharmacy, Nagpur for their immense support in this research.

\section{CONFLICT OF INTEREST}

The authors declare no conflict of interest.

\section{ABBREVIATIONS}

SEM: Scanning Electron Microscopy; XRD: X-ray Diffraction; DSC: Differential Scanning Calorimetry; SNF: Simulated Nasal Fluid; PBS: Phosphate Buffer Solution.

\section{REFERENCES}

1. Fornaro M, DeBerardis D, Perna G, Solmi M, Veronese N, Orsolini L, et al. Lurasidone in the treatment of bipolar depression: Systematic review of systematic reviews. Bio Med Res Int. 2017;3084859.

2. Greenberg WM, Citrome L. Pharmacokinetics and pharmacodynamics of lurasidone hydrochloride, a second-generation antipsychotic: A systematic review of the published literature. Clin Pharmacokinet. 2017;56(5):493-503.

3. Kirange RH, Chaudhari RB. Utilizing mucoadhesive polymers for nasal drug delivery system. Int J Pharm Sci Res. 2017;8(3):1012-22.

4. Singh G. Nasya Therapy-A Pharmacological Route for Drug Delivery to Brain. Journal Ayur Phys Surg. 2018;5(3):44-9.

5. Lokhande SS. A Review on Intranasal Drug Delivery System with Recent Advancement. Research J Top Cosmet Sci. 2018;9(1):12-8.

6. Joshi P, Badola A. Intranasal Route-An Innovative Technique for Brain Targeting. World J Pharm Res. 2017;6(17):300-16.

7. Kumar H, Mishra G, Sharma AK, Gothwal A, Kesharwani P, Gupta U. Intranasal drug delivery: A non-invasive approach for the better delivery of neurotherapeutics. Pharm Nanotechnol. 2017;5(3):203-14.

8. Moinuddin S, Razvi SH, Uddin MS, Fazil M, Shahidulla SM, Akmal MM. Nasal drug delivery system: A innovative approach. perception. Pharm Innovat J. 2019;8(3):169-77.

9. Mahale MM, Saudagar RB. Microsphere: A Review. J Drug Deliv Therapeut. 2019;9(3s):854-6.

10. Das MK, Ahmed AB, Saha D. Microsphere A Drug Delivery System-A Review. Int J Curr Pharm Res. 2019;11(4):34-41.

11. Salunke RD, Deshmukh MT, Shete RV, Solunke RS. Microspheres: A Review. Curr Pharm Res. 2019;9(2):2778-91.

12. Jassim ZE, Al-Akkam EJ. A review on strategies for improving nasal drug delivery systems. Drug Invent Today. 2018;10(s1):1-8.

13. Sharma S, Barman M, Singh N, Bhardwaj A, Mishra R, Singh M, et al. A Review on Mucoadhesive Microspheres as an Optimised Targeted Drug Delivery System. Indian J Pharm Biol Res. 2018;6(4):01-4.

14. Katsarov PD, Pilicheva BA, Uzunova YI, Gergov GH, Kassarova MI. Doxylamine/ Pyridoxine loaded chitosan microspheres as potential nasal drug delivery systems. Bulg Chem Commun. 2017;49:96-102.

15. Sharma M, Sharma N, Sharma A. Rizatriptan benzoate loaded natural polysaccharide based microspheres for nasal drug delivery system. Int J App Pharm. 2018;10(5):261-9.

16. Suryawanshi SR, Thakare NP, More DP, Thombre NA. Bioavailability enhancement of ondansetron after nasal administration of Caesalpinia pulcherrima-based microspheres. Drug Deliv. 2015;22(7):894-902.

17. Butani SH, Shah TO, Parmar KU, Rajput AM. Development ofrizatriptan benzoate microspheres for the nose to brain targeting. Int J Appl Pharm. 2016;8:69-74. 
18. Sharma N, Tyagi S, Gupta SK, Kulkarni GT, Bhatnagar A, Kumar N. Development and gamma-scintigraphy study of Hibiscus rosasinensis polysaccharide-based microspheres for nasal drug delivery. Drug Devel Indus Pharm. 2016;42(11):1763-71.

19. Mahajan HS, Dusunge SB, Gundare SA. Xyloglucan based Microspheres for Pulmonary Delivery of Rifabutin Dry Powder Inhaler. Int J Pharm Sci Nanotechnol. 2017;10(3):3709-14.

20. Mahapatra DK, Tijare LK, Gundimeda V, Mahajan NM. Rapid Biosynthesis of Silver Nanoparticles of Flower-like Morphology from the Root Extract of Saussurea lappa. Res Rev J Pharmacog. 2018;5(1):20-4.

21. Gangane PS, Kadam MM, Mahapatra DK, Mahajan NM, Mahajan UN. Design and formulating gliclazide solid dispersion immediate release layer and metformin sustained release layer in bilayer tablet for the effective postprandial management of diabetes mellitus. Int $\mathrm{J}$ Pharm Sci Res. 2018;9(9):3743-56.

22. Telrandhe R, Mahapatra DK, Kamble MA. Bombax ceiba thorn extract mediated synthesis of silver nanoparticles: Evaluation of anti-Staphylococcus aureus activity. Int J Pharm Drug Anal. 2017;5(9):376-9.

23. Jurišić DB, Mrak L, Winnicka K, Szekalska M, Juretić M, Filipović-Grčić J, et al. Spray-dried nanoparticle-loaded pectin microspheres for dexamethasone nasal delivery. Dry Technol. 2019;37(15):1915-25.

24. Mahajan NM, Pardeshi A, Mahapatra DK, Darode A, Dumore NG. Hypromellose and Carbomer induce bioadhesion of Acyclovir tablet to vaginal mucosa. Indo Am J Pharm Res. 2017;7(12):1108-18.
25. Dhawale P, Mahajan NM, Mahapatra DK, Mahajan UN, Gangane P. HPMC K15M and Carbopol 940 mediated fabrication of ondansetron hydrochloride intranasal mucoadhesive microspheres. J Appl Pharm Sci. 2018;8(08):075-83. 26. Kulkarni AD, Bari DB, Surana SJ, Pardeshi CV. In vitro, ex vivo and in vivo performance of chitosan-based spray-dried nasal mucoadhesive microspheres of diltiazem hydrochloride. J Drug Deliv Sci Technol. 2016;31:108-17.

27. Priya SP, Rajalakshmi AN, llaveni P. Formulation and evaluation of mucoadhesive microspheres of an anti-migraine drug. J Drug Deliv Therapeut. 2018;8(5):465-74.

28. Kaity S, Isaac J, Ghosh A. Interpenetrating polymer network of locust bean gum-poly (vinyl alcohol) for controlled release drug delivery. Carbohyd Polym. 2013;94(1):456-67.

29. Ige PP, Badgujar RR, Nerkar PP, Mahajan HS, Sonawane RO, Surana SJ. Study of physicochemical properties of flutamide-loaded Ocimum basilicum microspheres with ex vivo mucoadhesion and in vitro drug release. Part Sci Technol. 2018;36(5):583-91.

30. Dangre PV, Godbole MD, Ingale PV, Mahapatra DK. Improved dissolution and bioavailability of eprosartan mesylate formulated as solid dispersions using conventional methods. Indian J Pharm Edu Res. 2016;50(3):S209-17.

31. Umaredkar AA, Dangre PV, Mahapatra DK, Dhabarde DM. Fabrication of chitosan-alginate polyelectrolyte complexed hydrogel for controlled release of cilnidipine: A statistical design approach. Mater Technol. 2018;1.

\section{PICTORIAL ABSTRACT}

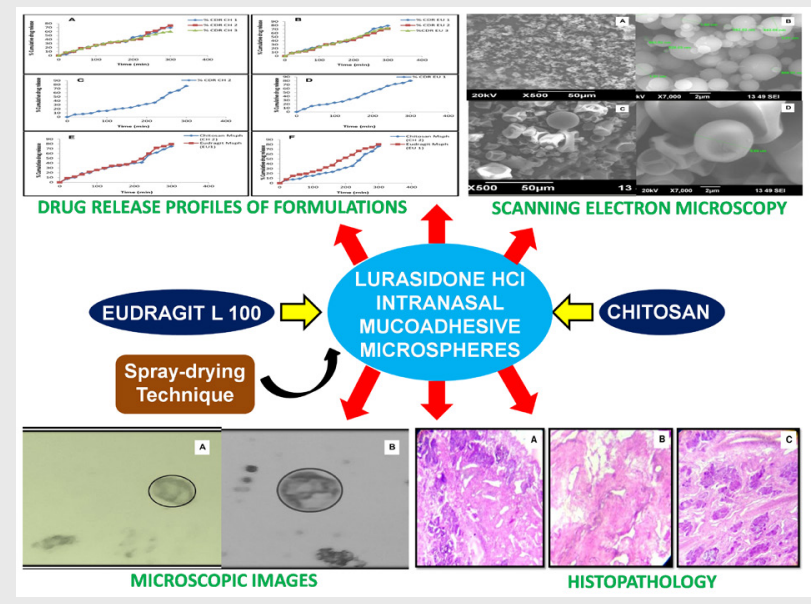

About Authors

\section{SUMMARY}

- Lurasidone $\mathrm{HCl}$ mucoadhesive microspheres of average particle size range $9.89 \mu \mathrm{m}$ to $15.3 \mu \mathrm{m}$ were produced from chitosan and Eudragit L 100 by spray-drying technique.

- Chitosan microsphere batch CH-2 showed $74.83 \%$ and Eudragit L 100 microsphere batch EU-1 showed $79.41 \%$ cumulative drug release in in vitro comparative study.

- Chitosan microsphere batch $\mathrm{CH}-2$ showed $76.36 \%$ and Eudragit L 100 microsphere batch EU-1 showed highest $80.18 \%$ cumulative drug release in ex vivo comparative drug permeation study.

- The in vitro drug release from both chitosan microspheres and Eudragit L 100 microspheres demonstrated zero-order kinetic model (nonFickian mechanism) of drug release.

- Histopathological study of the optimized formulation showed no deleterious response and adverse effect on nasal mucosa which reflected the safety feature of the fabricated microspheres.

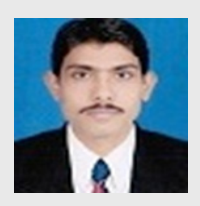

Purushottam Shridhar Gangane is working as an Associate Professor, Department of Pharmaceutics at Dadasaheb Balpande College of Pharmacy, Nagpur. He has more than 14 years of teaching and research experience. He has guided 18 post-graduate students under his supervision. He has published $15+$ research publications in the journals of repute and also authored several book chapters for international press. He has presented several papers in national as well as international conferences and received numerous awards. He is a life member of APTI and also a member of CRS-India Chapter. His areas of research expertise include nasal drug delivery and multiparticulate drug delivery system. 
Debarshi Kar Mahapatra is currently an Assistant Professor at Department of Pharmaceutical Chemistry, Dadasaheb Balpande College of Pharmacy, Nagpur. He taught medicinal and computational chemistry at undergraduate and post-graduate levels and has mentored numerous students in various research projects. He has published several research papers, review articles, imperative case-studies in various reputed national and international journals and authored many book chapters. He presented his original contributions at several international platforms, for which he received several awards by a number of scientific and professional bodies. He has contributed several edited books, textbooks, lab manuals, book chapters, and guide books on Medicinal Chemistry, Computational Chemistry, and Pharmaceutics. Presently, he is serving as reviewer and editorial board member for several journals of national and international repute.

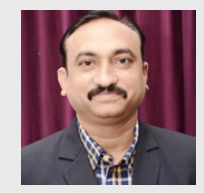

Nilesh Manoharrao Mahajan is working as a Professor and Head, Department of Pharmaceutics at Dadasaheb Balpande College of Pharmacy, Nagpur. He has 17+ years of teaching and research experience. He has guided $50+$ post-graduate students and 02 candidates are currently registered for Ph.D. He has received one international patent published on 'Herbal based mosquito repellent'; owns one design copyright for 'Robotic jaw for the in-vitro dissolution testing of chewing gum'; and also published $50+$ research publications in the journals of repute. He is a recipient of RPS by AICTE in the year 2013. He has presented many papers and received several awards in conferences. He is an editorial board member of two scientific journals. He is a life member of APTI and also a member of CRS-India Chapter. His areas of research expertise are nanotherapeutics, crystal engineering, and polyherbal formulations.

Cite this article: Khan S, Gangane PS, Mahapatra DK, Mahajan NM. Natural and Synthetic Polymers Assisted Development of Lurasidone Hydrochloride Intranasal Mucoadhesive Microspheres. Indian J of Pharmaceutical Education and Research. 2020;54(1):213-22. 